\title{
Unified Modelling of Flow Stress and Microstructural Evolution of 300M Steel under Isothermal Tension
}

\author{
Rongchuang Chen ${ }^{1, * \mathbb{D}}$, Shiyang Zhang ${ }^{1}$, Min Wang ${ }^{1,2, *}$, Xianlong Liu $^{1}$ and Fei Feng ${ }^{3}$ \\ 1 School of Materials Science \& Engineering, Hubei University of Automotive Technology, \\ Shiyan 442002, China; 202011104@huat.edu.cn (S.Z.); liuxianlong@huat.edu.cn (X.L.) \\ 2 State Key Laboratory of Materials Processing and Die \& Mould Technology, \\ Huazhong University of Science and Technology, Wuhan 430074, China \\ 3 College of Engineering, China Agricultural University, Beijing 100083, China; fengfei@hust.edu.cn \\ * Correspondence: cr@@hust.edu.cn (R.C.); minwang@126.com (M.W.); Tel.: +86-134-7628-4413 (R.C.)
}

Citation: Chen, R.; Zhang, S.; Wang, M.; Liu, X.; Feng, F. Unified Modelling of Flow Stress and Microstructural Evolution of $300 \mathrm{M}$ Steel under Isothermal Tension. Metals 2021, 11, 1086. https:// doi.org/10.3390/met11071086

Academic Editor: Hamid Assadi

Received: 1 June 2021

Accepted: 5 July 2021

Published: 7 July 2021

Publisher's Note: MDPI stays neutral with regard to jurisdictional claims in published maps and institutional affiliations.

Copyright: (c) 2021 by the authors. Licensee MDPI, Basel, Switzerland. This article is an open access article distributed under the terms and conditions of the Creative Commons Attribution (CC BY) license (https:// creativecommons.org/licenses/by/ $4.0 /)$.
Abstract: Constitutive models that reflect the microstructure evolution is of great significance to accurately predict the forming process of forging. Through thermal tension of $300 \mathrm{M}$ steel under various temperatures $\left(950 \sim 1150{ }^{\circ} \mathrm{C}\right)$ and strain rates $\left(0.01 \sim 10 \mathrm{~s}^{-1}\right)$, the material flow and microstructure evolutions were investigated. In order to describe both the exponential hardening phenomenon at a higher temperature, and the softening phenomenon due to recrystallization at a lower temperature, a constitutive model considering microstructure evolution was proposed based on the Kocks-Mecking model. It was found that considering the stress-strain curve to be exponential in the work-hardening stage could improve the constitutive model prediction precision. The average error was $2.43 \%$ (3.59 MPa), showing that the proposed model was more precise than the modified Arrhenius model and the Kocks-Mecking model. The models to describe recrystallization kinetics and average grain size were also constructed. This work enabled the Kocks-Mecking model to predict stress-strain curves with a higher accuracy, and broadened the applicable range of the Kocks-Mecking model.

Keywords: flow stress model; constitutive model; microstructure evolution; grain size

\section{Introduction}

The constitutive model is of great significance for the accurate prediction of the forming process of forgings. At the macro level, the flow behavior of steel is influenced by the process parameters (temperature, strain rate, strain, and holding time, etc.), and at the microscopic level the flow behavior is closely related to the evolution of the microstructure. Therefore, the development of an accurate constitutive model reflecting the evolution of the microstructure is important to improve the forming accuracy and serviceability of forging.

In recent years, various phenomenological constitutive models have been proposed, such as the Johnson-Cook (JC) model, Arrhenius model, Zerilli-Armstrong (ZA) model, artificial neural network (ANN) models and their modifications. Li et al. [1] used the JC model for the development of hot compression for Cr8Mo2SiV tool steel. Ahmadi et al. [2] compared the accuracy of the models (JC, ZA, ANN) in the prediction of flow stress in API 5CT-L80 steel and showed that the ANN model was more accurate. A similar work by Shokry et al. [3] also showed that the ANN model was more accurate compared with the JC model and the Arrhenius model in flow stress modelling of $10 \% \mathrm{Cr}$ steel. A modified JC model was proposed by Niu et al. [4], and an average absolute error of $1.46 \%$ was achieved. Fu et al. [5] developed a flow stress model that eliminated the effects of friction and adiabatic heating. Also using the Arrhenius model, Liu et al. [6] constructed a constitutive model that considered dynamic recrystallisation (DRX) softening during thermal compression.

Constitutive models reflecting microstructural evolution processes have attracted a great deal of attention in the control of material flow and microstructure in forgings. At 
high temperatures, the flow stress of steel is influenced by the evolution of dislocations and grain size. The accumulation of dislocations at grain boundaries accelerates the formation of recrystallization cores and triggers DRX, while atomic rearrangement during recrystallisation reduces dislocation density and grain size. Therefore, there is a complex relationship between dislocation density, grain size and recrystallization. Softening and hardening are a reflection of the microstructural evolution of the material, and by quantifying the hardening and softening phenomena of the material, it is possible to be informed of the microstructural evolution occurring within the material and to reduce the complexity of metallographic characterization in industrial applications. Chen et al. [7] modified the Laasraoui-Jonas dislocation density model and applied it to the modelling of compressive flow stresses in X12 steel. Muyu et al. [8] distinguished the softening mechanism of B1500HS steel into dynamic recovery (DRV) and DRX, and they established the constitutive relationship based on the Estrin-Mecking (EM) model [9]. Also based on the EM model, Zhang et al. [10] calculated the flow stresses in Cr-Mn-Si-Ni steel under high temperature tension. Yang et al. [11] quantified the softening behavior and microstructural evolution of GCr15 steel wire rods during rolling and found that sub-dynamic recrystallisation and static recrystallisation (SRX) played an important role in interpass softening. Xu et al. [12] developed a modified kinetic equation to predict the SRX softening behavior of $12 \mathrm{Cr}$ rotor steel. Su et al. [13] modelled the dislocation density evolution of Fe-Mn-Al-C steel in tension, and accurately predicted the flow stresses. Considering the glide and climb of dislocations, Surya et al. [14] predicted the flow stresses in $304 \mathrm{HCu}$ steel in high temperature stretching. The results showed that the evolution of flow stresses was mainly influenced by the mobile and forest dislocation motion. In Muhammad's work [15], they proposed a damage based constitutive model incorporating DRX kinetics and predicted the flow stresses in $16 \mathrm{MnCrS5}$ steel for different hot working parameters. Sumeet et al. [16] described the strain hardening behavior of an aluminum alloy through a dislocation-based model using forest dislocation density and mobile dislocation density as internal variables. In addition, Ziyad et al. [17] considered dislocation evolution at grain boundaries and within grains. Similarly, in the research of He et al. [18], dislocation density was considered as an independent state variable and an intrinsic constitutive model based on physical mechanisms was proposed. Hyuk et al. [19] introduced forward, reverse and latent dislocations into the constitutive model and modelled tensile-compressive stress-strain curves for non-proportional loading of metal sheets.

The 300M steel, a kind of low-alloyed steel which has excellent strength $\left(\sigma_{\text {yield }} \geq 1800 \mathrm{MPa}\right)$, toughness, and fatigue performance [20], is usually used in large structural parts in industrial applications. For 300M steel, Liu et al. [21] investigated the effects of temperature, strain, strain rate, initial grain size, and interpass holding time on the interpass holding softening of $300 \mathrm{M}$ high-strength steel by double-pass compression tests, and established a sub-dynamic recrystallization kinetic model. Liu et al. [22] studied the effect of SRX on the interpass softening of 300M steel and established a SRX kinetic model. Luo et al. [23] integrated DRX, SRX and sub-dynamic recrystallisation models in DEFORM software to simulate the grain evolution of $300 \mathrm{M}$ steel landing gear in pre-forging and final forging. Zhao et al. $[24,25]$ researched the microstructure evolution of $300 \mathrm{M}$ steel during interpass holding after double-pass compression tests, and established SRX and sub-dynamic recrystallization grain size models. Zeng et al. [26] studied the effect of interpass holding on the softening of $300 \mathrm{M}$ steel, and established a constitutive model based on the internal variable model. Chen et al. [27] carried out multi-pass compression tests and established a constitutive model by considering the microstructure evolution processes such as DRX, sub-dynamic recrystallization and SRX. Besides, the authors developed a constitutive model for 300M steel under tension based on the Arrhenius model [28].

This work presents a constitutive model of a typical ultra-high strength steel, $300 \mathrm{M}$ steel, which exhibited extinct differences in flow behavior under various tensile conditions. Based on the evolution of average dislocation density, the Kocks-Mecking model was modified to describe both the exponential hardening phenomenon at a higher temperature, and the softening phenomenon due to DRX at a lower temperature. It was found that a 
parameter in the Kocks-Mecking model was actually related to the hardening index $(n)$ and should be a variable under different deformation conditions. This study enables the Kocks-Mecking model to predict stress-strain curves with a higher accuracy, and broadens the applicable range of the Kocks-Mecking model.

\section{Materials and Methods}

\subsection{Material}

The ingot $(\Phi 300 \mathrm{~mm})$ was received in an as-forged state, and the composition was tested to be $93.982 \mathrm{Fe}-2.562 \mathrm{Si}-0.896 \mathrm{Cr}-0.824 \mathrm{Ni}-0.808 \mathrm{Mn}-0.435 \mathrm{Mo}-0.39 \mathrm{C}-0.086 \mathrm{~V}-0.017 \mathrm{~S}$ (weight \%). Tensile samples were cut from half-radius of the ingot, as shown in Figure 1.

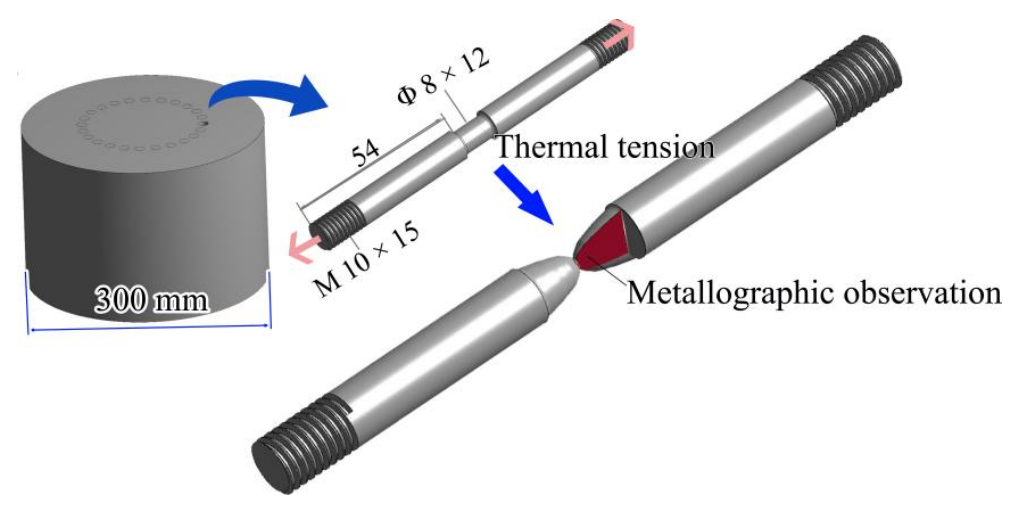

Figure 1. Experimental procedure.

\subsection{Thermal Tension Experiment}

Tensile experiments were performed on a Gleeble 3500 simulator (Dynamic Systems Inc., New York, NY, USA). The temperature range and strain rate range were selected at 950 1150 ${ }^{\circ} \mathrm{C}$ and $0.01 \sim 10 \mathrm{~s}^{-1}$, respectively. The thermal mechanical process was shown in Figure 2. During the experiment, test sample was heated to $1200{ }^{\circ} \mathrm{C}$, held there for $4 \mathrm{~min}$ to homogenize microstructure, and cooled to deformation temperatures. The austenitising condition of $1200{ }^{\circ} \mathrm{C}$ for 4 min was chosen because the authors' previous results [29] showed that austenitising can occur quickly and completely under this condition. The specimen was heated by electricity. The temperature was measured by a thermal couple welded near the deformation zone of the specimen and monitored by a computer. The error of temperature measurement was claimed to be within $\pm 1^{\circ} \mathrm{C}$. To measure the diameter of the necking area, a gauge was clamped in the middle of the specimen. The tensile force was applied in both ends of the notched sample by threads, and once cracking appeared in the central region of the sample, the sample was water quenched. In total, 20 groups of tensile tests were carried out.

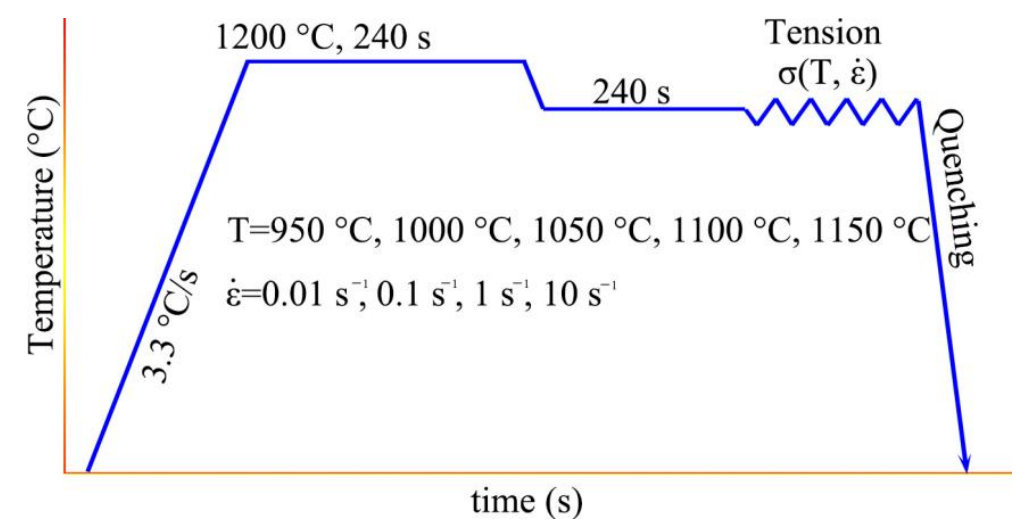

Figure 2. Illustration of the thermal mechanical process. 


\subsection{Stress and Strain Correction}

In the tensile test, serious necking occurred in the central region of the specimen. If the specimen was still considered to be cylindrical, in other words, the necking effect was neglected, there will be a large deviation between the measured value and the real value of stress. The logarithmic strain was corrected by:

$$
\varepsilon=\ln \left(A_{0} / A\right)
$$

where, $A_{0}$ and $A$ represented the initial and the real time cross-sectional area during tension, respectively. The value of $A_{0}$ was calculated from the diameter of the neck of the specimen, which was measured with a gauge during the experiment. To better understand the strain distribution, the tensile process was simulated by a finite elemental software, DEFORM, and the cross-sectional effective strain contour was shown in Figure 3. It could be seen that, when the distance from point $A$ increased, the effective strain gradually increased from 0 to 3. It was worth noting that the shape of the distance-strain curve was similar with the cross-sectional shape of the sample after tension, because only a small part of plastic deformation extended to the adjacent area due to a weak work-hardening (WH) effect. Moreover, the result of the finite elemental analysis showed that the contour curve of the specimen coincided with the changing curve of the minimum cross-sectional diameter. Figure 4 showed the comparison of stress-strain curve before and after correction at $1050{ }^{\circ} \mathrm{C}$ and $0.1 \mathrm{~s}^{-1}$.

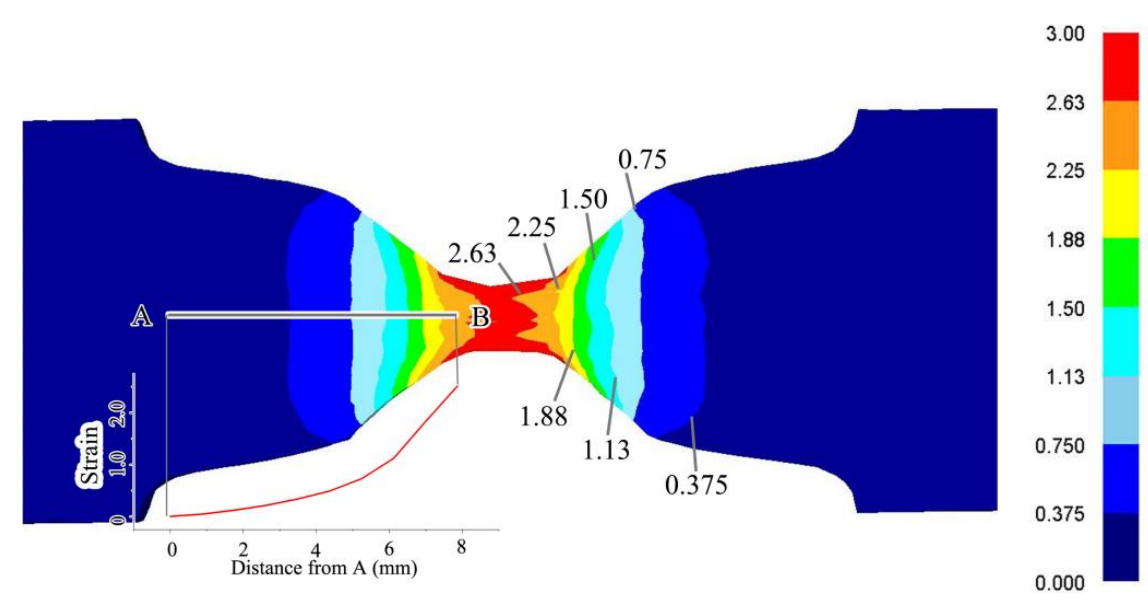

Figure 3. Simulated effective strain contour.

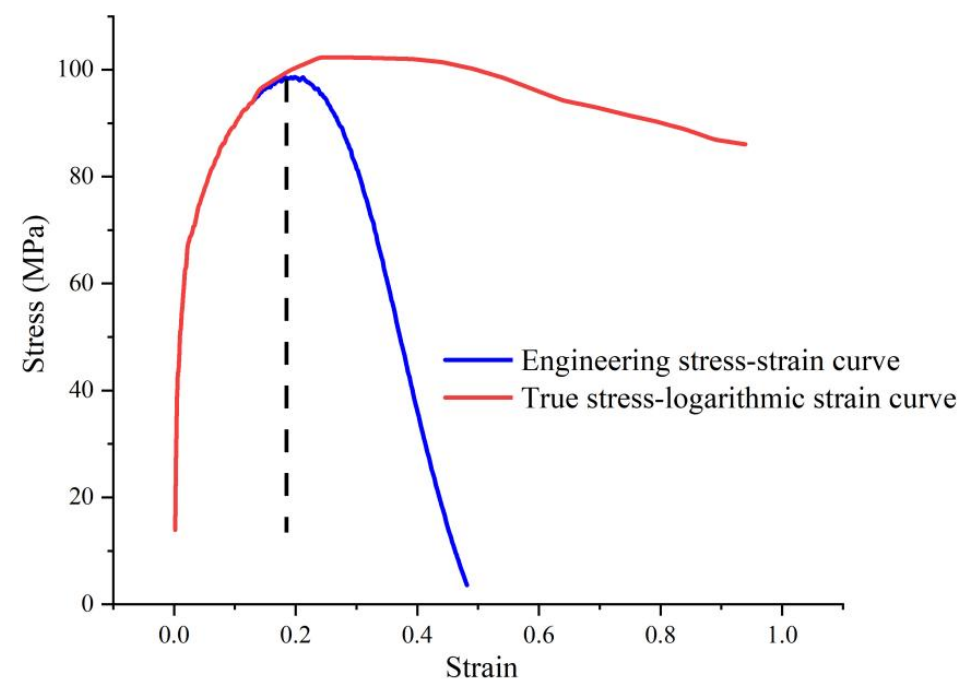

Figure 4. Stress-strain curves before and after correction at $1050{ }^{\circ} \mathrm{C}, 0.1 \mathrm{~s}^{-1}$. 


\subsection{Microstructure Observation}

The microstructure near the necking area of the specimen, as indicated in Figure 1, was inspected by a standard metallographic procedure. The sample was ground by 200 \#, 400 \#, 800 \#, 1200 \#, and 2000 \# abrasive papers. Then, the sample was polished by a polishing cloth, and etched in etchant, in which the volume ratio of saturated picric acid, carbon tetrachloride, and liquid detergent (Nice Group Co., Lishui City, China) was 5:1:1, additionally with one drop of hydrochloric acid for every $30 \mathrm{~mL}$ etchant. The etching temperature was $35^{\circ} \mathrm{C}$. The microstructure photos were taken on an optical microscope (VHX-1000C, Keyence Co., Osaka, Japan). At least 5 photos were taken for each specimen. The average grain size was measured by the truncation method according to the ASTM 112-13 standard. The microstructure after holding for $240 \mathrm{~s}$ at $1200{ }^{\circ} \mathrm{C}$ was shown in Figure 5. Equiaxed austenite grains were obtained before tension, and the average grain size was $68 \mu \mathrm{m}$.

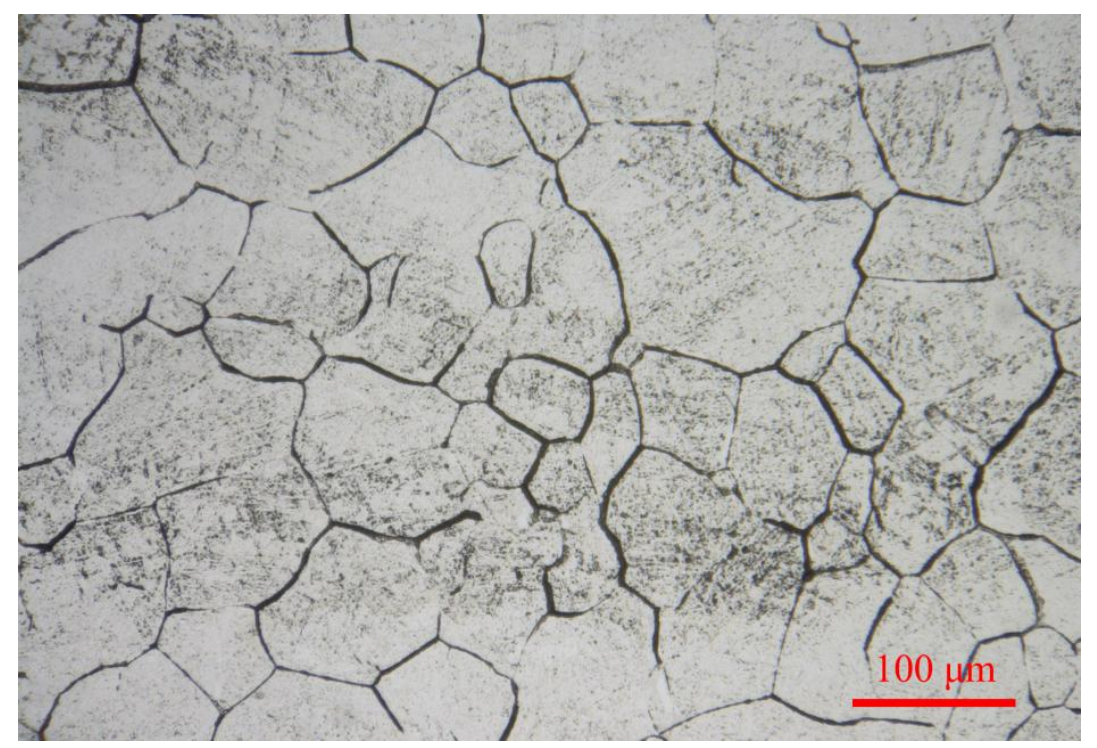

Figure 5. Microstructures of the material after holding for $240 \mathrm{~s}$ at $1200{ }^{\circ} \mathrm{C}$.

\section{Results}

\subsection{Flow Behavior}

The stress-strain curves of $300 \mathrm{M}$ steel in tension under various process conditions were shown in Figure 6. Under a lower strain rate, as shown in Figure 6a, the stress gradually increased until the stress reached a peak. Then the stress dropped slowly and eventually remained stable. The single-peaked stress-strain curves in Figure 6a suggested that the material had been dynamically recrystallized, especially at a high temperature $\left(1150{ }^{\circ} \mathrm{C}\right)$. The curves were crossed under several conditions, proving that temperature and strain rate not only affected the thermal activation effect of the material, but also had an effect on the recrystallization process, thus affecting the evolution of stress. Under a higher strain rate, as shown in Figure 6b, the curve shapes were similar, and the stress increased with the strain. A monotonous rising curve usually implied a relatively strong $\mathrm{WH}$ process, while the softening effect was weak. The difference in curve shapes in Figure $6 a, b$ was the result of the competition effect of dislocation multiplications due to cross-slips, and dislocation annihilation due to DRV and DRX. It could be explained that, at a higher strain rate, DRV and DRX were not complete due to the short deformation time, and the hardening effect was more obvious, while at a lower strain rate, DRV and DRX were complete, and the hardening effect by the dislocation cross-slips was quickly eliminated. 


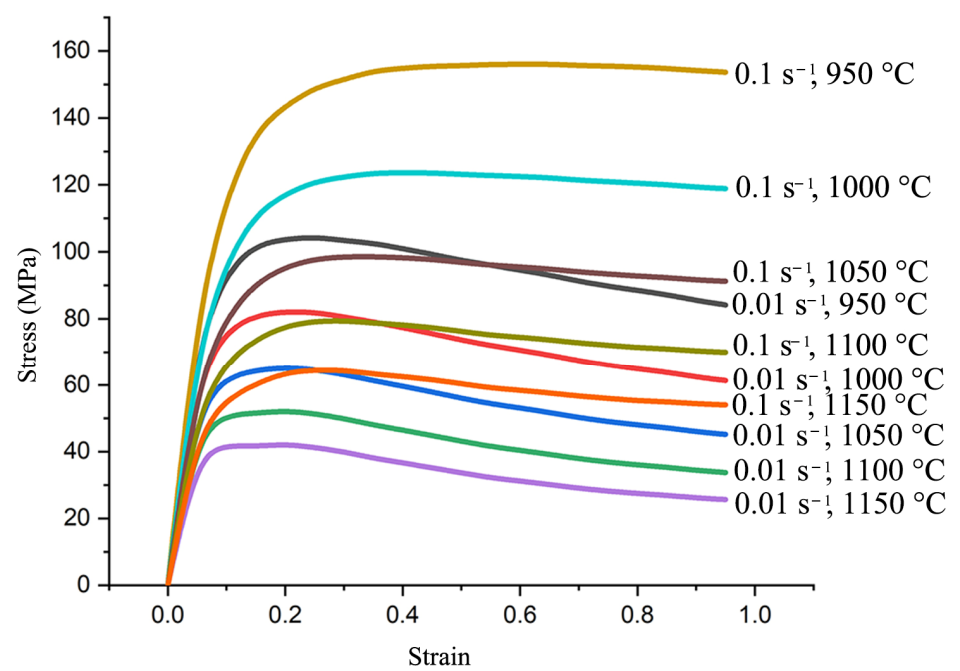

(a)

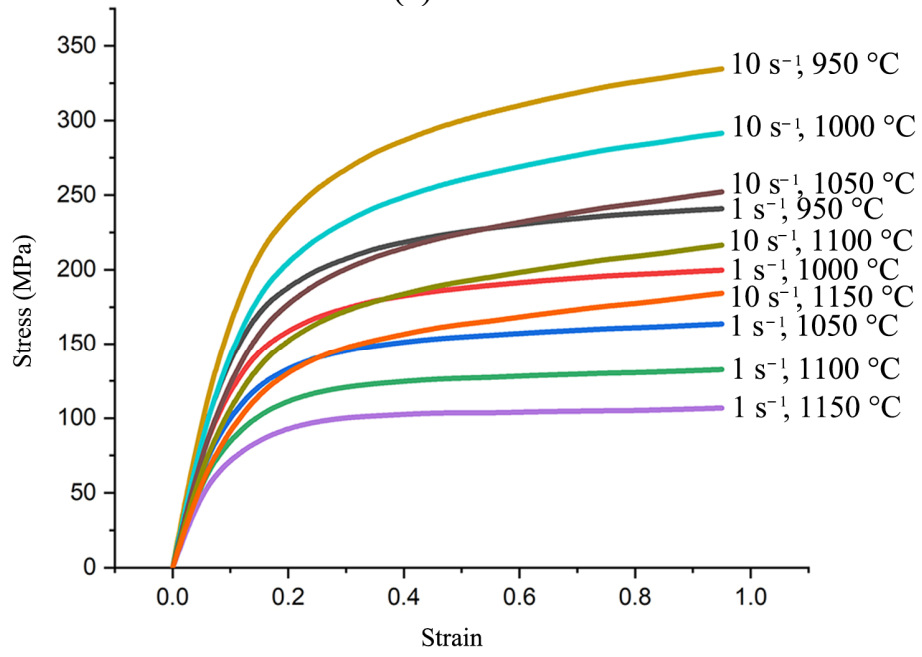

(b)

Figure 6. Flow behaviors of $300 \mathrm{M}$ steel in tension under (a) lower strain rates, (b) higher strain rates.

\subsection{Microstructure Evolution}

The microstructures of 300M steel after tension were shown in Figures 7 and 8. Small recrystallized microstructures could be found around the initial grain boundaries under lower temperatures, and coarse grains were generated under higher temperatures, proving that the material has been dynamically recrystallized and resulting in changes in the microstructure morphology and the average size. By comparison of the results in Figure 7 , it could be seen that the size of recrystallized grain and the volume fraction (VF) of recrystallized grain increased with increasing temperature. This was because, as the temperature increased, the atomic thermal motion and dislocation mobility were more intense, and the energy barriers needing to be overcome to trigger recrystallization were lower. Thus, the DRX was more complete under a higher temperature. Moreover, it could be seen in Figure $8 \mathrm{~b}$ that a lot of small, recrystallized grains occurred near the coarse grain boundaries. However, the recrystallization was insufficient, resulting a mixed grain microstructure. In order to obtain a uniform and full recrystallized microstructure, deformation amount should be increased under a lower temperature. Under a higher strain rate (Figure 8d), the recrystallized microstructure was not obvious due to the short deformation time. Comparing the results in Figure 8, it could be seen that recrystallization was more complete when the deformation temperature was high $\left(1150{ }^{\circ} \mathrm{C}\right)$. The average grain size gradually decreased with increasing strain rate, because the recrystallized grain did not grow sufficiently. The average grain size after tension were shown in Figure 9. 

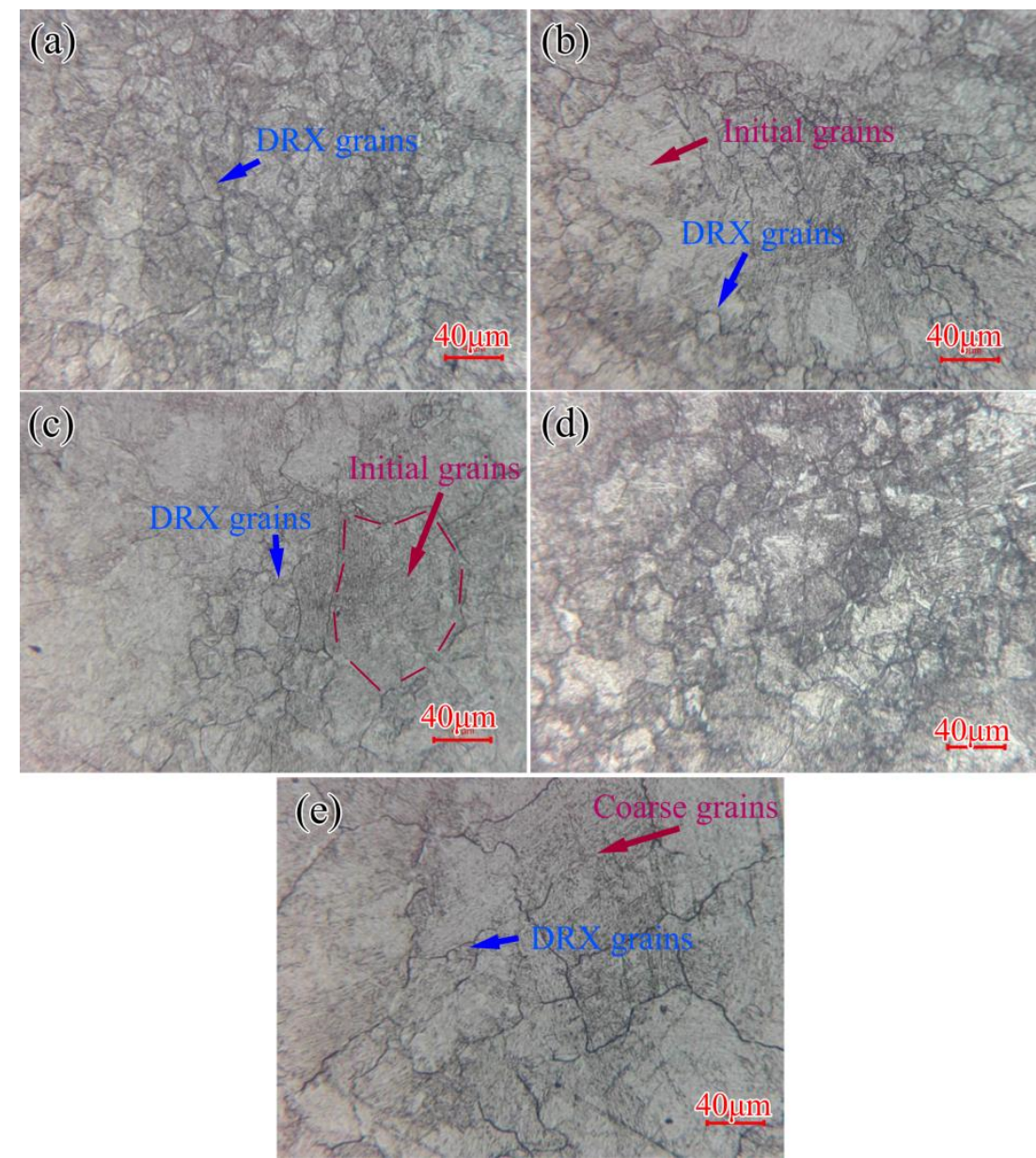

Figure 7. Microstructures of $300 \mathrm{M}$ steel after tension under $0.1 \mathrm{~s}^{-1}$ and (a) $950{ }^{\circ} \mathrm{C}$, (b) $1000{ }^{\circ} \mathrm{C}$, (c) $1050{ }^{\circ} \mathrm{C}$, (d) $1100{ }^{\circ} \mathrm{C}$, (e) $1150{ }^{\circ} \mathrm{C}$.
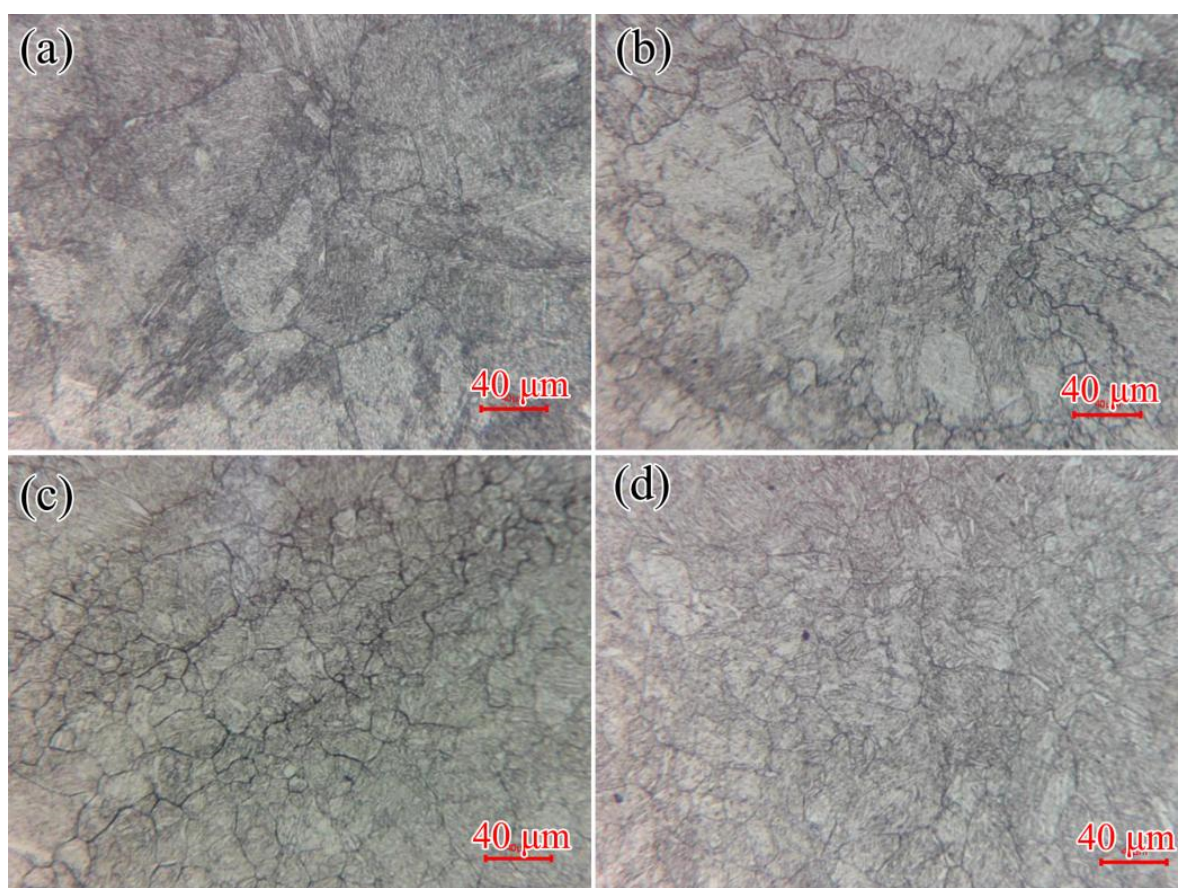

Figure 8. Microstructures of $300 \mathrm{M}$ steel after tension under $1000{ }^{\circ} \mathrm{C}$ and (a) $0.01 \mathrm{~s}^{-1}$, (b) $0.1 \mathrm{~s}^{-1}$, (c) $1 \mathrm{~s}^{-1}$, (d) $10 \mathrm{~s}^{-1}$. 


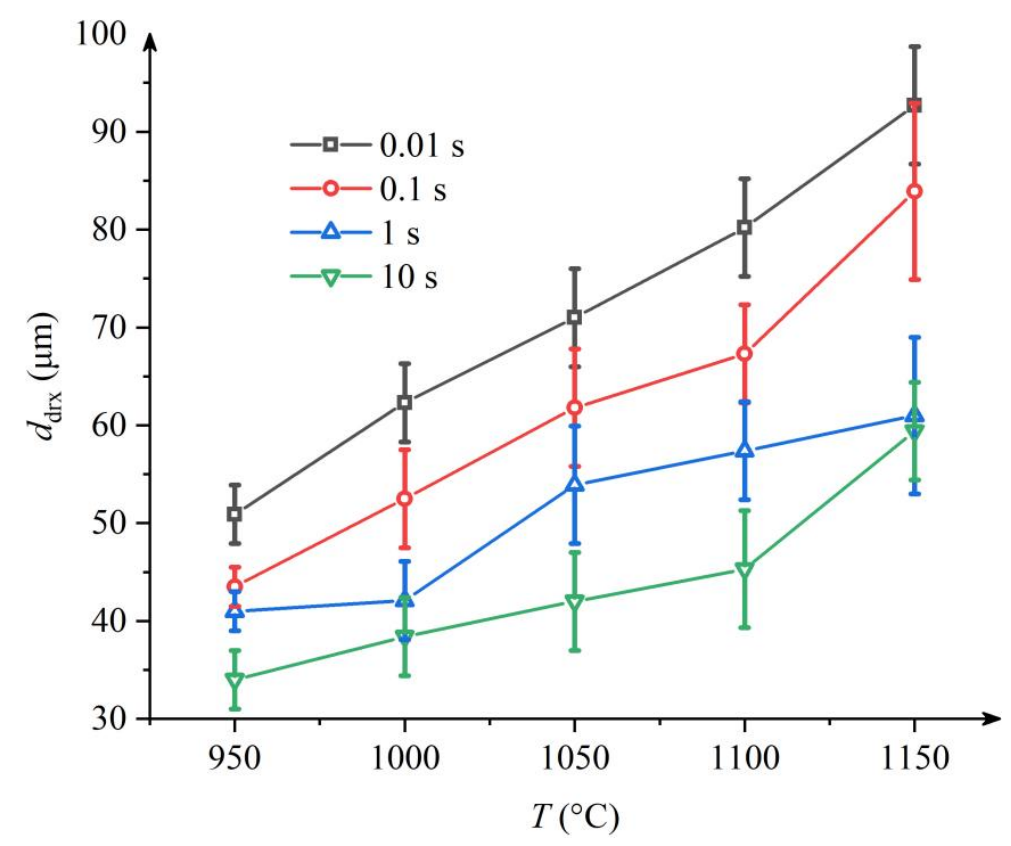

Figure 9. Average grain size of $300 \mathrm{M}$ steel after thermal tension.

\section{Discussion}

\subsection{Proposed Constitutive Model}

The stress of steel is influenced by dislocation density evolution. The accumulation of dislocations near grain boundaries accelerates the formation of recrystallized cores and triggers DRX. Meanwhile, the atom rearrangement in the recrystallization process will reduce the dislocation density and grain size. So, there is a coupled relationship between dislocation density, grain size, and DRX kinetics. Hardening and softening reflect the overall level of the dislocation annihilation and multiplication. For low stacking fault energy materials, dislocation cross-slips lead to hardening, while DRV and DRX result in softening. Compared with the complex work of microstructure characterizations, it is economical and convenient to learn about the microstructure changes within materials by hardening and softening reflected by the flow behavior. However, it is very difficult to distinguish between the influences of different microstructure evolution processes on material flow behavior. One solution would be to deform at a low temperature, so that only WH occurs, and DRV softening does not occur. However, the ultimate elongation is small at a low temperature, and a stress-strain curve for statistical purpose can hardly be obtained. What is more, to distinguish the effect of DRX on softening, the plastic strain needs to be lower than the critical strain of DRX. These problems hinder the efforts to distinguish the influences of microstructure evolution on hardening and softening of steel. Another solution is to make the material fully recrystallized, so that DRX does not further soften the material, and in this way, the influence of DRX could be separated. According to Sakai et al. [30], DRX resulted in single-peaked stress-strain curves, and the stress remained basically stable after dynamic full recrystallization. By adding a DRX term to the Kocks-Mecking model, the precise prediction of the single peaked stressstrain curves of metals [31,32] could be realized. However, the test results showed that under $1 \sim 10 \mathrm{~s}^{-1}$ and $1100 \sim 1150{ }^{\circ} \mathrm{C}$, the stress was increasing even after recrystallization completed. Difficulties were encountered in determining the DRX kinetics using previous methods, and constitutive model could not be precisely constructed, so the model needed to be improved. 
In the present research, the stress-strain curve was exponential when only dislocation cross-slips occurred, in other words, when the softening caused by DRX and DRV did not occur. The relationship between the stress and strain satisfied:

$$
\sigma=\gamma \varepsilon^{n}
$$

where, $n$ was the hardening index. As shown in Figure 10, if $n$ equaled 1, the material was pure elastic, and the stress-strain curve satisfied the Hook's law. If $n$ equaled 0 , the material was pure plastic, and the stress did not increase with increasing strain. For general elastic-plastic materials, for example, the $300 \mathrm{M}$ steel, when only dislocation cross-slips occurred, $n$ should be between 0 and 1 .

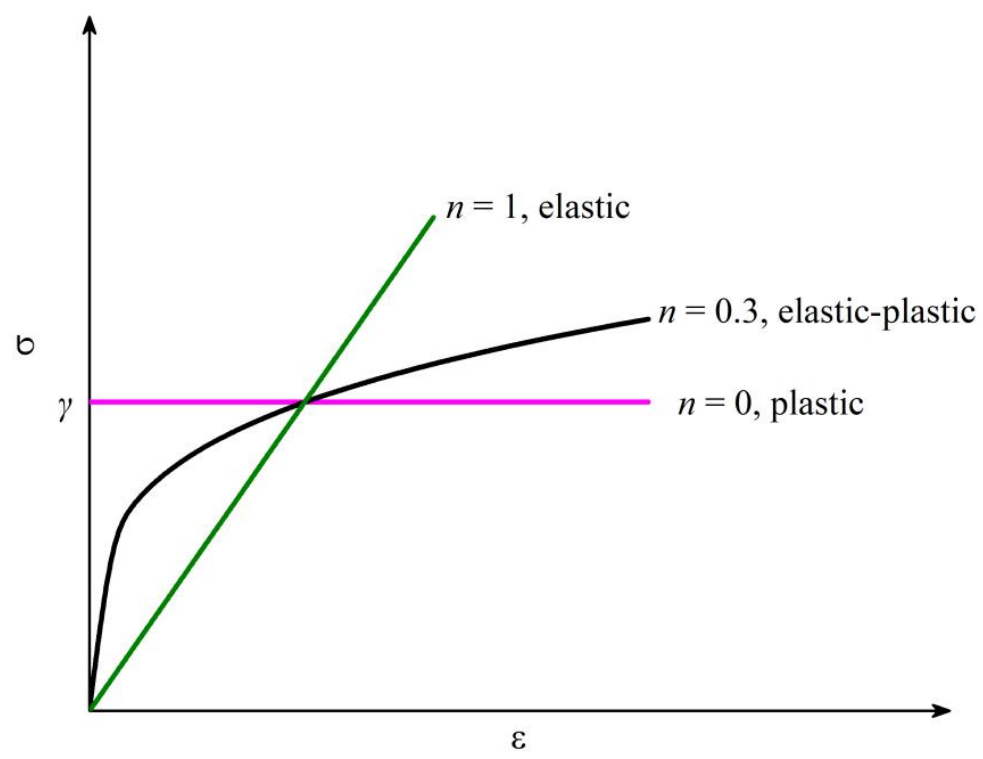

Figure 10. The relationship between the hardening index $n$ and the shape of the stress-strain curve.

Replacing $\sigma$ with $\alpha \mu M b \sqrt{\rho}$ according to the Taylor's Equation $(\sigma=\alpha \mu M b \sqrt{\rho})$, the evolution equation of average dislocation density was:

$$
\rho=\frac{\sigma^{2}}{(\alpha \mu M b)^{2}}=\frac{\gamma^{2}}{(\alpha \mu M b)^{2}} \varepsilon^{2 n}
$$

Substituting $\frac{\gamma^{2}}{(\alpha \mu M b)^{2}}$ with $\vartheta$ :

$$
\rho=\vartheta \varepsilon^{2 n}
$$

Derive Equation (4) with respect to $\varepsilon$ :

$$
\dot{\rho}_{+}=2 n \vartheta \varepsilon^{2 n-1}
$$

Substitute $\rho$ for $\frac{\gamma^{2}}{(\alpha \mu M b)^{2}} \varepsilon^{2 n}$ according to Equation (3):

$$
\dot{\rho}^{+}=2 n \vartheta^{2} \rho^{\frac{2 n-1}{2 n}}
$$

The dislocation density annihilation by DRV was [33]:

$$
\dot{\rho}^{-}=k_{2} \rho
$$


The dislocation density annihilation by DRX was proportional to recrystallization kinetics, $X[32]$ :

$$
\dot{\rho}_{\mathrm{drx}}^{-}=k_{3} X
$$

where, $k_{2}$ and $k_{3}$ were model parameters. Substitute $\frac{2 n-1}{2 n}$ for $m$, and $2 n \vartheta^{2}$ for $k_{1}$, a model was proposed:

$$
\dot{\rho}=k_{1} \rho^{m}-k_{2} \rho-k_{3} X
$$

where, $X$ was the DRX kinetics, which can be expressed as:

$$
X=1-\mathrm{e}^{-0.693\left(\frac{\varepsilon-\varepsilon_{C}}{\varepsilon_{p}}\right)^{p}}
$$

where, $\varepsilon_{p}$ was the peak strain, $\varepsilon_{c}\left(\right.$ equaled $\left.0.83 \varepsilon_{p}\right)$ was the critical strain to initiate DRX, and $p$ was a constant related to DRX kinetics. $k_{1}, k_{2}$, and $k_{3}$ could be expressed as:

$$
\begin{aligned}
& k_{1}=\mathrm{A}_{1} \dot{\varepsilon}^{\mathrm{n}_{1}} \exp \left(\frac{\mathrm{Q}_{1}}{\mathrm{RT}}\right) \\
& k_{2}=\mathrm{A}_{2} \dot{\varepsilon}^{\mathrm{n}_{2}} \exp \left(\frac{\mathrm{Q}_{2}}{\mathrm{RT}}\right) \\
& k_{3}=\mathrm{A}_{3} \dot{\varepsilon}^{\mathrm{n}_{3}} \exp \left(\frac{\mathrm{Q}_{3}}{\mathrm{RT}}\right)
\end{aligned}
$$

$m$ was a constant associated with the material hardening index $n\left(m=\frac{2 n-1}{2 n}\right)$, and could be expressed as:

$$
m=\mathrm{A}_{\mathrm{m}} \dot{\varepsilon}^{\mathrm{n}_{\mathrm{m}}} \exp \left(\frac{\mathrm{Q}_{\mathrm{m}}}{\mathrm{RT}}\right)
$$

In the above equations, $\mathrm{A}, \mathrm{n}$, and $\mathrm{Q}$ with sub-scripting indexes were constants. $\dot{\varepsilon}$ was the strain rate, $R$ equaled $8.314 \mathrm{~J} /(\mathrm{mol} \mathrm{K})$. Compared with the Kocks-Mecking model, a third term $\left(\dot{\rho}_{\mathrm{drx}}^{-}\right)$was added. Besides, the value of $m$ was 0.5 for the Kocks-Mecking model, and $m$ was smaller than 0.5 for the proposed model. Finally, the flow stress could be calculated according to the Taylor's Equation:

$$
\sigma=\mu M \alpha b \sqrt{\rho}
$$

where, $\mu$ was the shear modulus equaled $(86.94-0.027 T) \mathrm{GPa}, M$ was the Taylor factor equaled 3.06, $\alpha$ was a constant equaled 0.3 , and $b$ was the Burgess vector equaled $2.54 \times 10^{-10} \mathrm{~m}$.

\subsection{Application of the Model}

The flow stress could be calculated in an iterative way according to Equations (9) and (15). To solve the nineteen model unknown parameters in the model, a solution process was established on MATLAB (Figure 11). Firstly, the initial value for the optimization parameter $P$ was assigned:

$$
P=\left[\mathrm{A}_{0}, \mathrm{n}_{0}, \mathrm{Q}_{0}, \mathrm{~A}_{1}, \mathrm{n}_{1}, \mathrm{Q}_{1}, p, \mathrm{~A}_{2}, \mathrm{n}_{2}, \mathrm{Q}_{2}, \mathrm{~A}_{3}, \mathrm{n}_{3}, \mathrm{Q}_{3}, \mathrm{~A}_{\mathrm{m}}, \mathrm{n}_{\mathrm{m}}, \mathrm{Q}_{\mathrm{m}}, \mathrm{A}_{\mathrm{c}}, \mathrm{n}_{\mathrm{c}}, \mathrm{Q}_{\mathrm{c}}\right]
$$

The flow stress under each hot working parameter was calculated, and the prediction error was evaluated. Then, the parameter $P$ was updated by nonderivative method, and the prediction error was evaluated again. Through multiple iterations, the parameter $P$ was optimized to obtain a minimum prediction error. The optimized parameters were shown in Table 1. 


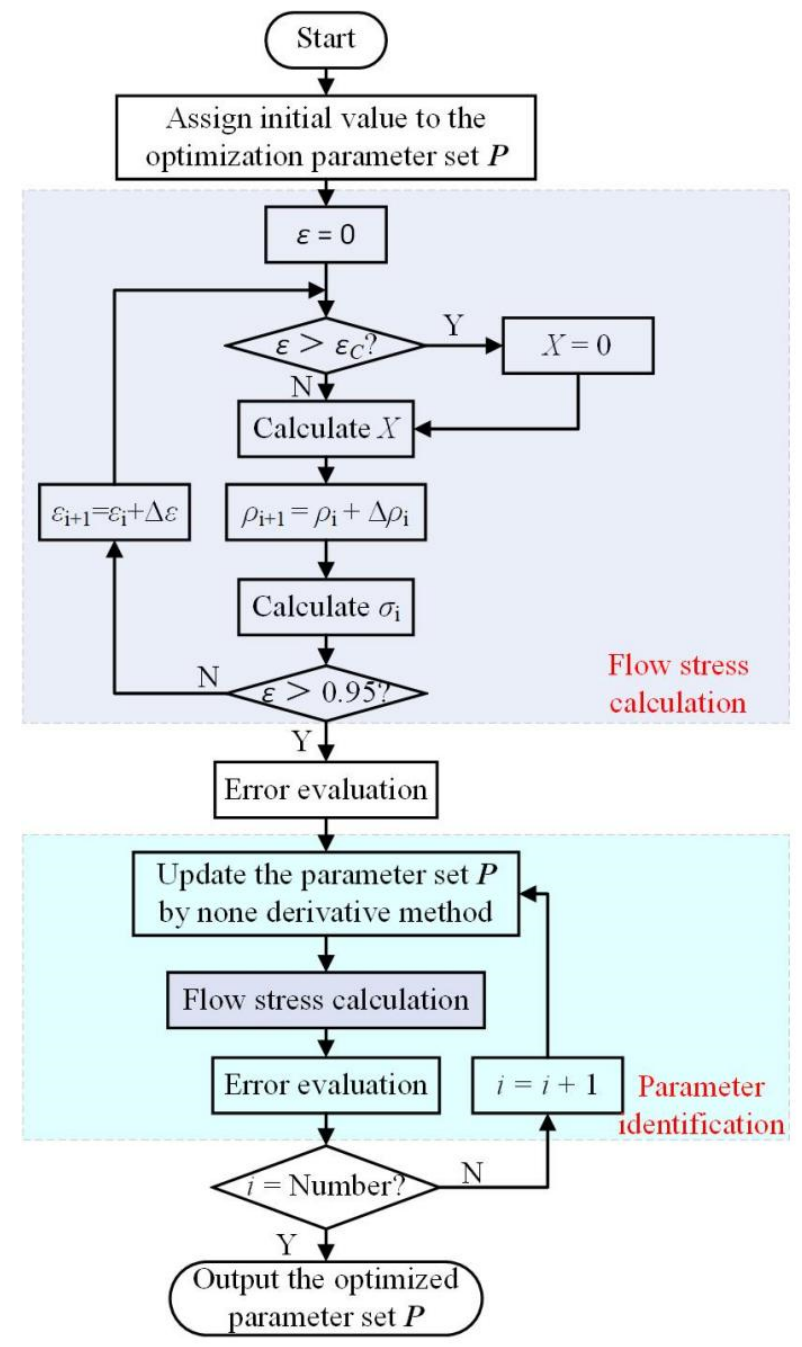

Figure 11. The optimization process of the model parameters.

Table 1. Model parameters.

\begin{tabular}{cccccc}
\hline Variable & Value & Variable & Value & Variable & Value \\
\hline $\mathrm{A}_{0}$ & 1.2285 & $\mathrm{~A}_{2}$ & $7.4777 \times 10^{2}$ & $\mathrm{~A}_{\mathrm{m}}$ & 1.3134 \\
$\mathrm{n}_{0}$ & $5.9855 \times 10^{-2}$ & $\mathrm{n}_{2}$ & $-2.0641 \times 10^{-1}$ & $\mathrm{n}_{\mathrm{m}}$ & $1.1998 \times 10^{-2}$ \\
$\mathrm{Q}_{0}$ & $7.3975 \times 10^{5}$ & $\mathrm{Q}_{2}$ & $2.1902 \times 10^{5}$ & $\mathrm{Q}_{\mathrm{m}}$ & $-1.1242 \times 10^{6}$ \\
$\mathrm{~A}_{1}$ & $2.8097 \times 10^{2}$ & $\mathrm{~A}_{3}$ & $4.9810 \times 10^{11}$ & $\mathrm{~A}_{\mathrm{c}}$ & $1.7561 \times 10^{-1}$ \\
$\mathrm{n}_{1}$ & $-1.1584 \times 10^{-1}$ & $\mathrm{n}_{3}$ & $-2.0642 \times 10^{-2}$ & $\mathrm{n}_{\mathrm{c}}$ & $2.4686 \times 10^{-1}$ \\
$\mathrm{Q}_{1}$ & $-1.6120 \times 10^{6}$ & $\mathrm{Q}_{3}$ & $-3.3120 \times 10^{6}$ & $\mathrm{Q}_{\mathrm{c}}$ & $6.2823 \times 10^{4}$ \\
$p$ & 1.4268 & & & & \\
\hline
\end{tabular}

The model prediction results in Figure 12 showed that the calculated stress agreed well with the experimental stress. At low stress levels, the calculation error was relatively low compared with the error at high stress levels, because the average percentage error was used in error evaluation. By using the absolute error, the error at high stress levels could be decreased, but the overall percentage error would be increased. The experimental and calculated stresses were compared by scatter plots in Figure 13. It could be seen that these points are located near the $45^{\circ}$ line. The average percentage error was $2.43 \%$, and the average absolute error was $3.59 \mathrm{MPa}$. The proposed model showed an advantage in precision compared with the modified Arrhenius model $(6.23 \%, 6.81 \mathrm{MPa})$ and the Kocks-Mecking model $(6.59 \%, 5.37 \mathrm{MPa})$ in previous literatures [28,32]. 


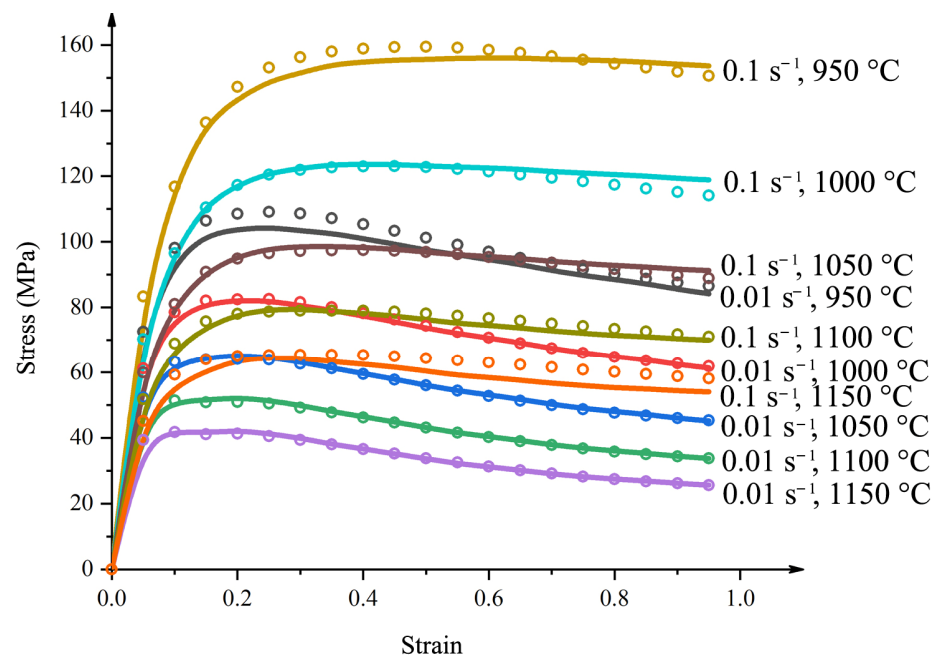

(a)

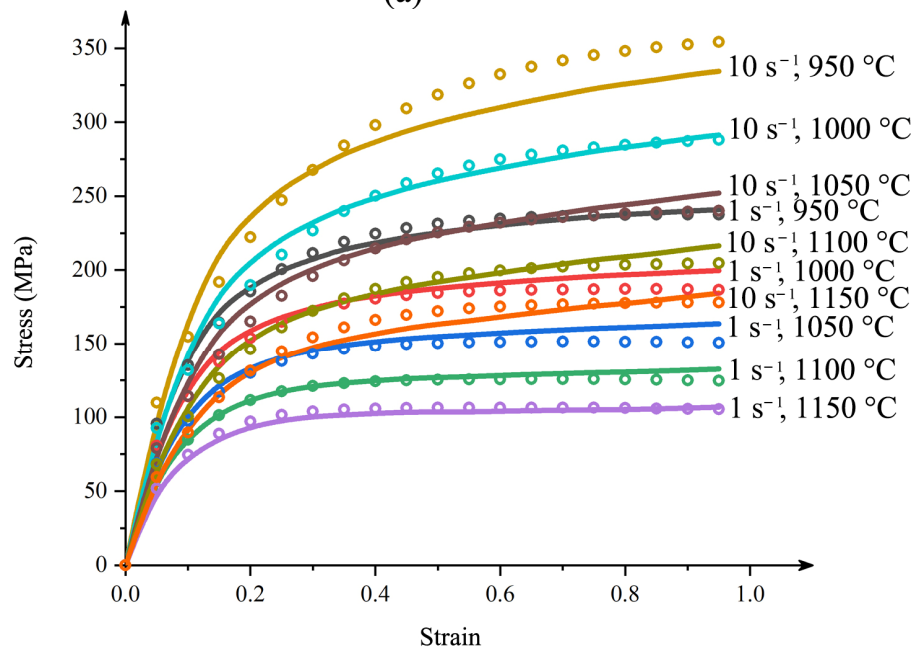

(b)

Figure 12. Comparison of experimental and calculated stress under (a) lower strain rates, (b) higher strain rates. Dots denoted calculated data, and lines denoted experimental data.

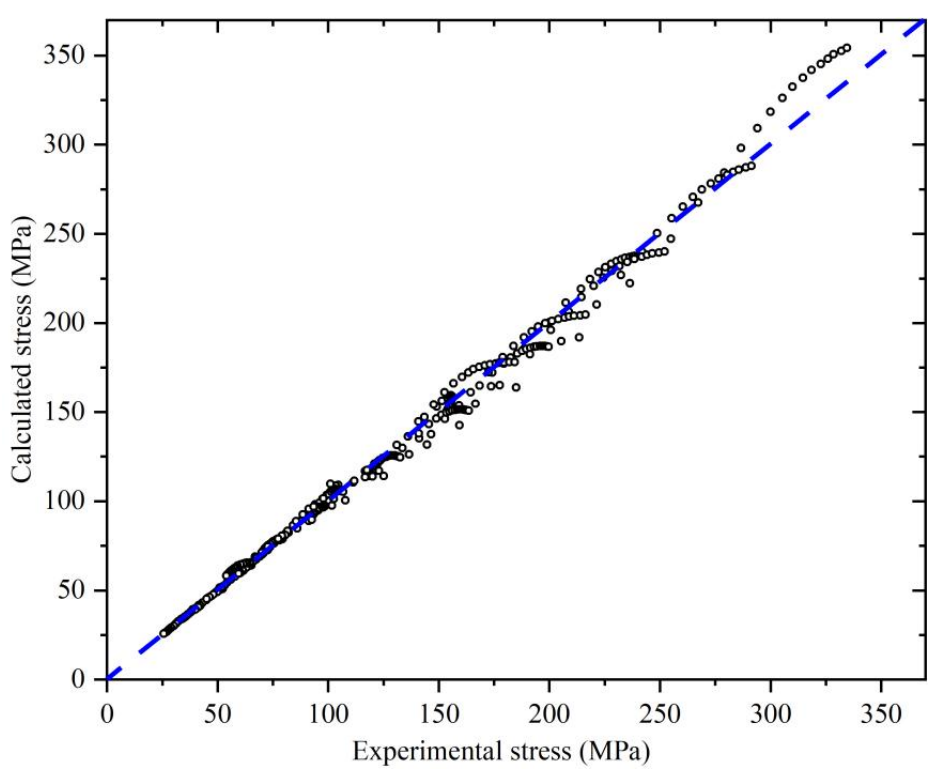

Figure 13. Comparison of experimental and calculated stress. 
The hardening index (n) under various tensile deformation conditions was shown in Table 2. The value of $n$ equaled 1 for the Kocks-Mecking model, and $n$ was in the range of 0.75-0.88 for the proposed model. It could be concluded that considering the stress-strain curve to be exponential in the WH stage could improve the prediction accuracy.

Table 2. The value of $n$ for $300 \mathrm{M}$ steel.

\begin{tabular}{ccccc}
\hline \multirow{2}{*}{$\left({ }^{\circ} \mathbf{C}\right)$} & \multicolumn{3}{c}{$\dot{\varepsilon}\left(s^{-\mathbf{1}}\right)$} \\
\cline { 2 - 5 } & $\mathbf{0 . 0 1}$ & $\mathbf{0 . 1}$ & $\mathbf{1}$ & $\mathbf{1 0}$ \\
\hline 950 & 0.75 & 0.76 & 0.77 & 0.78 \\
1000 & 0.77 & 0.78 & 0.79 & 0.81 \\
1050 & 0.78 & 0.79 & 0.82 & 0.83 \\
1100 & 0.81 & 0.82 & 0.83 & 0.85 \\
1150 & 0.83 & 0.85 & 0.86 & 0.88 \\
\hline
\end{tabular}

The contribution of $\mathrm{WH}, \mathrm{DRV}$, and DRX on the flow stress of $300 \mathrm{M}$ steel under $1050{ }^{\circ} \mathrm{C}$ and $0.01 \mathrm{~s}^{-1}$ was schematically shown in Figure 14. It could be seen that when only WH occurred, the stress-strain curve increased very quickly, as the strain increased from 0 to 0.1 . Then, the softening effect by DRV balanced the hardening effect as the strain increased from 0.1 to 0.2 . The softening effect by DRX resulted in a decrease of the stress.

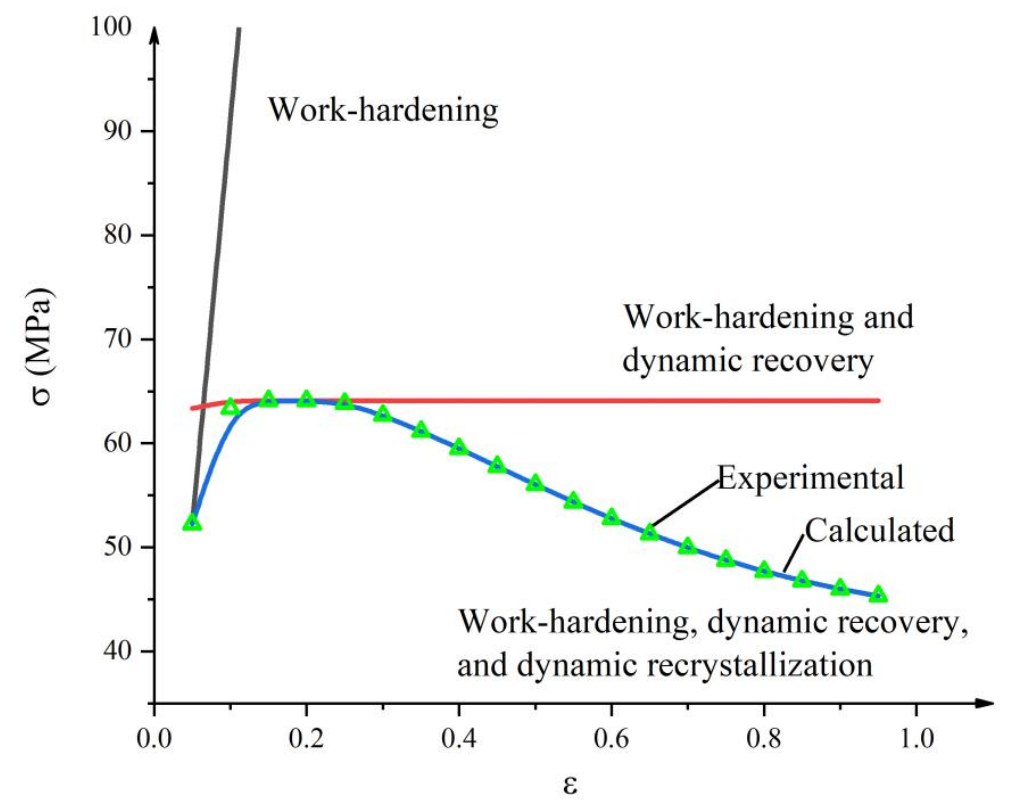

Figure 14. The contribution of $\mathrm{WH}, \mathrm{DRV}$, and DRX under $1050{ }^{\circ} \mathrm{C}$ and $0.01 \mathrm{~s}^{-1}$.

The DRX kinetics model was determined to be:

$$
\begin{gathered}
X=1-\mathrm{e}^{-0.693\left(\frac{\varepsilon-\varepsilon_{\mathcal{C}}}{\varepsilon p}\right)^{1.4268}} \\
\varepsilon_{\mathcal{C}}=0.17561 \dot{\varepsilon}^{0.24686} \exp \left(\frac{62823}{\mathrm{R} T}\right) \\
\varepsilon_{p}=\varepsilon_{c} / 0.83
\end{gathered}
$$

The DRX kinetics was drawn in Figure 15. It could be seen that the DRX critical strain was smaller at a lower temperature and at a higher strain rate, and the volume fraction (VF) of recrystallized grains generally increased with increasing strain. The VF increased with increasing temperature, because under a higher temperature the atomic thermal motion and dislocation mobility were more intense, and the energy barriers needed to be 
overcome to trigger recrystallization were lower. The VF was lower under $10 \mathrm{~s}^{-1}$, because the deformation time was short $(0.1 \mathrm{~s})$, and the recrystallization could not occur sufficiently. The calculated result of Figure 15 was consistent with the metallographic results showed in Figure 9.

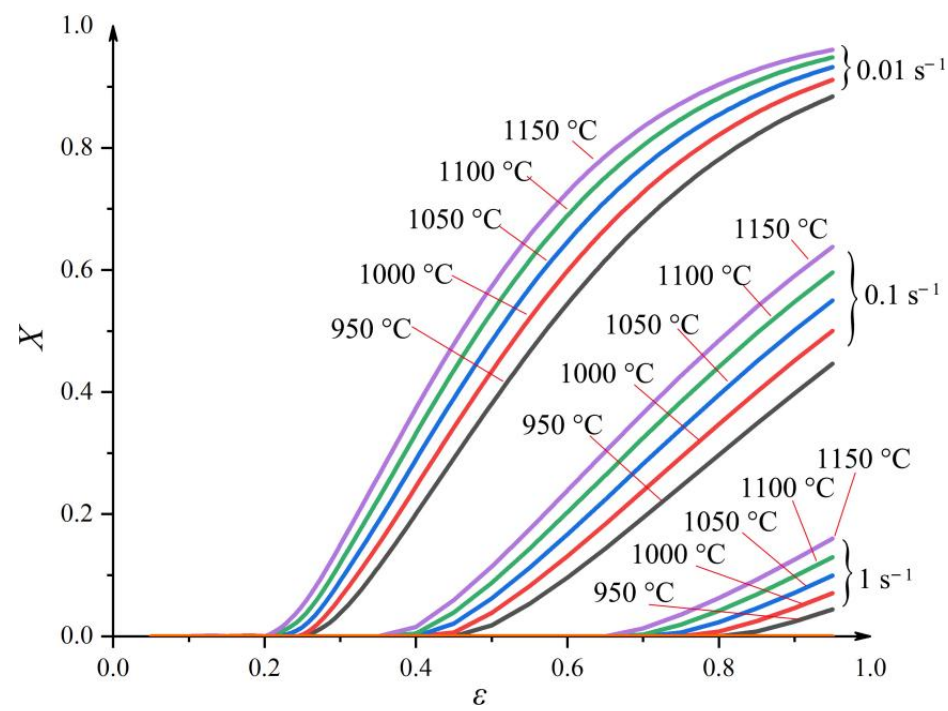

Figure 15. Dynamic recrystallization kinetics of 300M steel in tension.

\subsection{Modelling of Recrystallized Grain Size}

The average size of recrystallized grains was expressed as:

$$
d_{d r x}=\mathrm{A}_{\mathrm{drx}} \dot{\varepsilon}^{\mathrm{n}_{\mathrm{drx}}} \exp \left(\frac{\mathrm{Q}_{\mathrm{drx}}}{\mathrm{RT}}\right)
$$

where, $\mathrm{A}_{\mathrm{drx}}, \mathrm{n}_{\mathrm{drx}}$, and $\mathrm{Q}_{\mathrm{drx}}$ were model parameters.

Take the natural logarithm of both sides of Equation (20):

$$
\ln \left(d_{d r x}\right)=\ln \left(\mathrm{A}_{\mathrm{drx}}\right)+\mathrm{n}_{\mathrm{drx}} \ln (\dot{\varepsilon})+\frac{\mathrm{Q}_{\mathrm{drx}}}{\mathrm{RT}}
$$

We drew the scatter plot of $\ln (\dot{\varepsilon})$ versus $\ln \left(\mathrm{d}_{\mathrm{drx}}\right)$, and linearly fit the points under various temperatures. The value of $n_{d r x}$ could be obtained by the mean slope. The calculation procedure of $n_{d r x}$ was shown in Figure 16. It could be seen that $\ln \left(d_{d r x}\right)$ basically decreased linearly with increasing $\ln (\dot{\varepsilon})$. The mean slope was -0.07125 , so $\mathrm{n}_{\mathrm{drx}}$ equaled -0.07125 .

We drew the scatter plot of $\frac{1}{R T}$ versus $\ln \left(\mathrm{d}_{\mathrm{drx}}\right)$, and linearly fit the points under various strain rates. The value of $Q_{d r x}$ could be obtained by the mean slope. The calculation procedure of $Q_{d r x}$ was shown in Figure 17. It could be seen that $\ln \left(d_{d r x}\right)$ decreased with increasing $\ln (\dot{\varepsilon})$. The mean slope was -40632 , so $\mathrm{Q}_{\mathrm{drx}}$ equaled $-40632 \mathrm{~J} /(\mathrm{mol} \mathrm{K})$. 


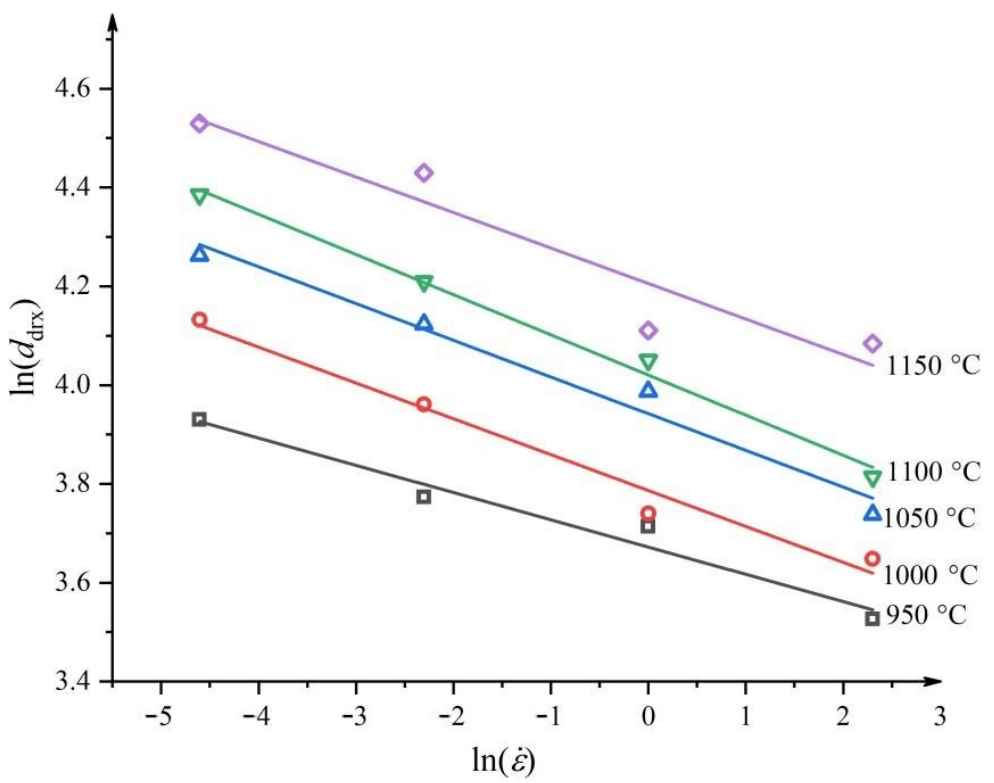

Figure 16. Calculation procedure of $\mathrm{n}_{\mathrm{drx}}$.

We drew the scatter plot of $\left(n_{d r x} \ln (\dot{\varepsilon})+\frac{Q_{d r x}}{R T}\right)$ versus $\ln \left(d_{d r x}\right)$, and linearly fit the points. The value of $\ln \left(A_{d r x}\right)$ could be obtained by the intercept. The calculation procedure of $\ln \left(A_{d r x}\right)$ was shown in Figure 18. It could be seen that $\ln \left(d_{d r x}\right)$ increased with increasing $\mathrm{n}_{\mathrm{drx}} \ln (\dot{\varepsilon})+\frac{\mathrm{Q}_{\mathrm{drx}}}{\mathrm{RT}}$. The intercept of the fitted line was 7.6276, so $\mathrm{A}_{\mathrm{drx}}$ equaled 2054.02. Thus, the recrystallized grain size model was:

$$
\mathrm{d}_{\mathrm{drx}}=2054.02 \dot{\varepsilon}^{-0.07125} \exp \left(\frac{-40632}{\mathrm{RT}}\right)
$$

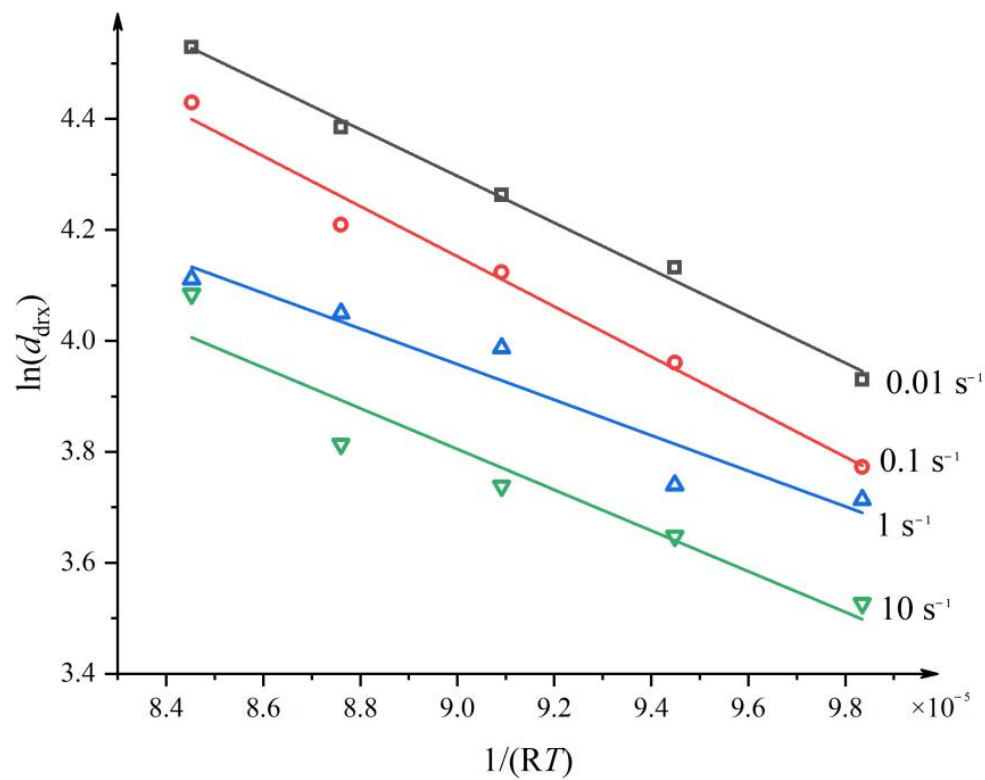

Figure 17. Calculation procedure of $\mathrm{Q}_{\mathrm{drx}}$. 


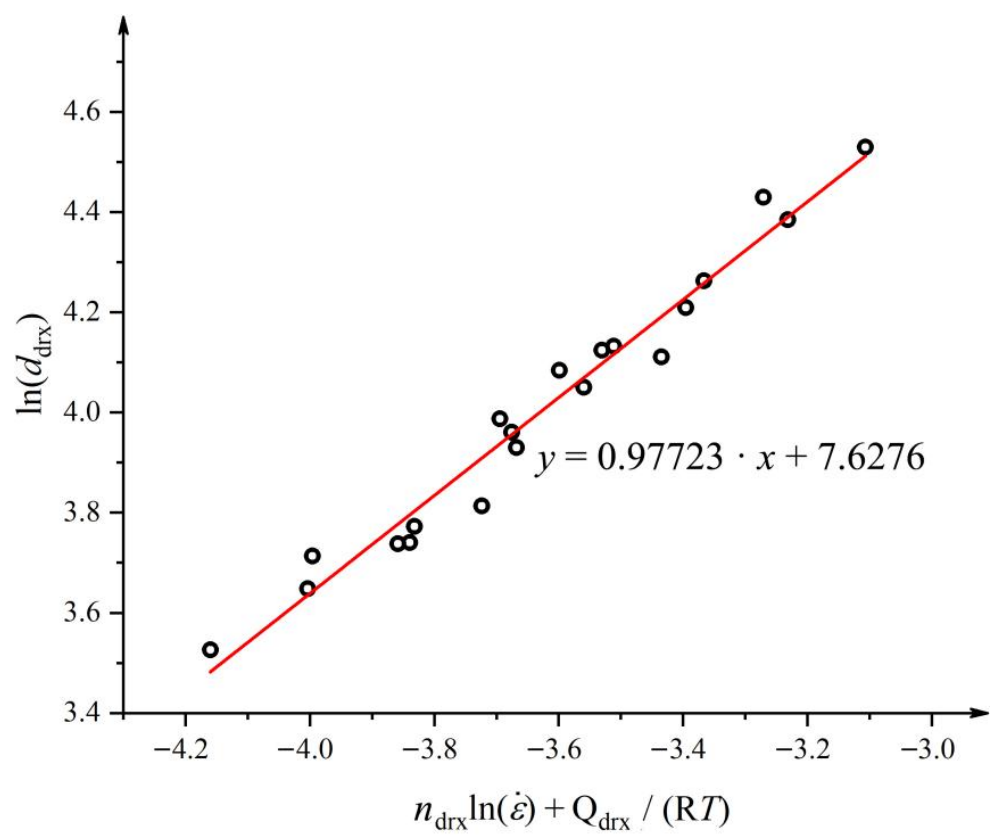

Figure 18. Calculation procedure of $\ln \left(\mathrm{A}_{\mathrm{drx}}\right)$.

The comparison of the calculated value and experimental value of recrystallized grain size was shown in Figure 19. It could be seen that the average grain size model was accurate. The confidence level [28] evaluating the accuracy of the model, $R$, was calculated to be 0.97 , showing the model precision was acceptable. The average error was $3.84 \%$ $(2.04 \mu \mathrm{m})$. The model prediction error may come from (a) the statistical error due to not big enough area for metallographic observation, (b) the error caused by occasional factors in the experiment. By repeating the test, the model error could be reduced.

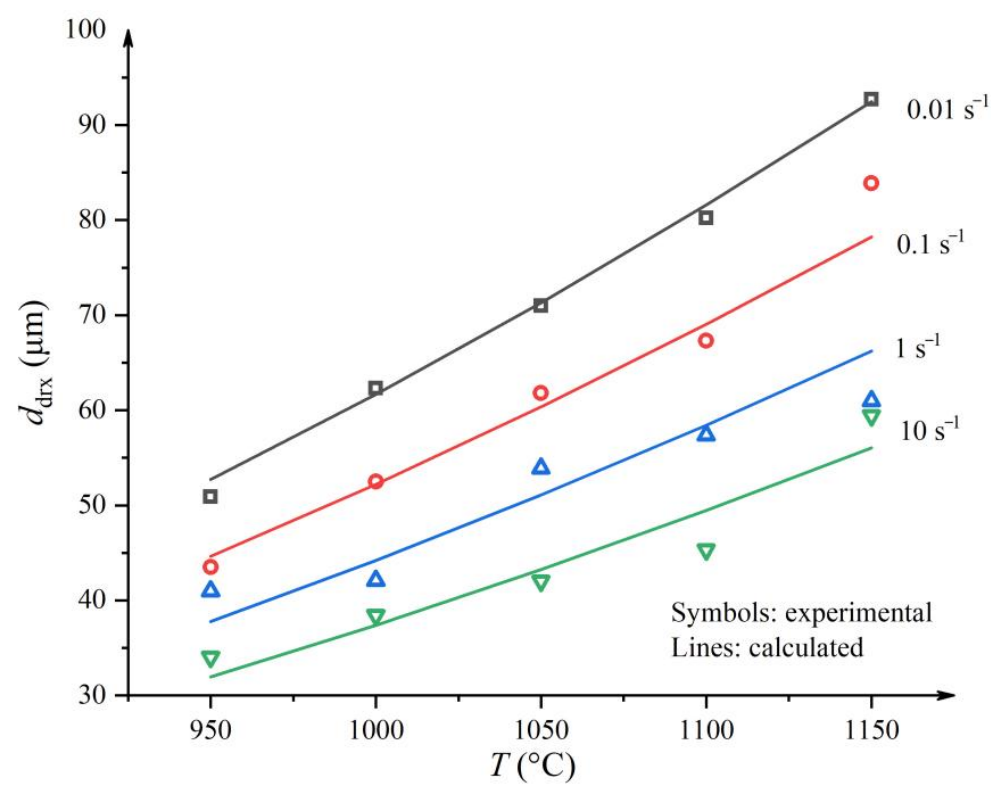

Figure 19. Comparison of the calculated value and experimental value of recrystallized grain size.

\section{Conclusions}

The following conclusions could be drawn by thermal tension of $300 \mathrm{M}$ steel:

(1) Single-peaked stress-strain curves were obtained at a lower strain rate, while monotonous rising curves were obtained at a higher strain rate because of the competition of dislocation multiplication due to cross-slips and dislocation annihilation due to DRV and DRX. 
(2) Under a higher deformation temperature, the average size of DRX grains increased, and the volume fraction of DRX grain increased. Under a higher strain rate, the recrystallized grain did not grow sufficiently.

(3) A dislocation based constitutive model incorporating microstructure evolution was proposed, and the proposed model was applied in thermal tension of $300 \mathrm{M}$ steel. Results showed that the proposed model was accurate. The average error of flow stress prediction was $2.43 \%$ ( $3.59 \mathrm{MPa})$. The proposed model was more precise compared with the modified Arrhenius model $(6.23 \%, 6.81 \mathrm{MPa})$ and the KocksMecking model (6.59\%, 5.37 MPa).

(4) The dynamic recrystallization kinetics model was determined:

$$
\begin{gathered}
X=1-\mathrm{e}^{-0.693\left(\frac{\varepsilon-\varepsilon_{c}}{\varepsilon_{p}}\right)^{1.4268}} \\
\mathcal{E}_{\mathcal{c}}=0.17561 \dot{\varepsilon}^{0.24686} \exp \left(\frac{62823}{\mathrm{R} T}\right) \\
\varepsilon_{p}=\varepsilon_{c} / 0.83
\end{gathered}
$$

The average size of recrystallized grains was described as:

$$
d_{d r x}=2054.02 \dot{\varepsilon}^{-0.07125} \exp \left(\frac{-40632}{\mathrm{R} T}\right)
$$

The average error was 3.84\% $(2.04 \mu \mathrm{m})$, and the value of $\mathrm{R}$ was calculated to be 0.97 . So, the constructed model was accurate.

Author Contributions: Conceptualization, R.C. and S.Z.; methodology, R.C.; software, X.L.; validation, F.F.; formal analysis, X.L.; Investigation, R.C. and X.L.; Writing—original draft preparation, R.C. and S.Z.; writing-review \& editing, M.W. and F.F.; funding acquisition, M.W. and F.F. All authors have read and agreed to the published version of the manuscript.

Funding: This work was funded by the Hubei Provincial Natural Science Foundation (2020CFB374), the National Natural Science Foundation of China (51705169), the Key Laboratory of Automotive Power Train and Electronic in Hubei University of Automotive Technology (ZDK1202005), the State Key Laboratory of Materials Processing and Die \& Mould Technology in Huazhong University of Science and Technology (P2020-05, P2021-023), the Outstanding Young Scientific \& Technological Innovation Team Plan of Colleges and Universities in Hubei Province (T201518), and the Doctoral Scientific Research Fund of Hubei University of Automotive Technology (BK202005).

Institutional Review Board Statement: Not applicable.

Informed Consent Statement: Not applicable.

Data Availability Statement: The raw/processed data required to reproduce these findings cannot be shared at this time as the data also forms part of an ongoing study.

Conflicts of Interest: The authors declare no conflict of interest.

\section{References}

1. Li, C.-S.; He, S.; Ren, J.; Han, Y. The Flow Stress Behavior and Constitutive Model of Cr8Mo2SiV Tool Steel during Hot Deformation. Steel Res. Int. 2021, 92, 2000434. [CrossRef]

2. Ahmadi, H.; Ashtiani, H.R.; Heidari, M. A comparative study of phenomenological, physically-based and artificial neural network models to predict the Hot flow behavior of API 5CT-L80 steel. Mater. Today Commun. 2020, 25, 101528. [CrossRef]

3. Shokry, A.; Gowid, S.; Kharmanda, G.; Mahdi, E. Constitutive Models for the Prediction of the Hot Deformation Behavior of the 10\%Cr Steel Alloy. Materials 2019, 12, 2873. [CrossRef]

4. Niu, L.; Cao, M.; Liang, Z.; Han, B.; Zhang, Q. A modified Johnson-Cook model considering strain softening of A356 alloy. Mater. Sci. Eng. A 2020, 789, 139612. [CrossRef]

5. Fu, Q.; Yuan, W.; Xiang, W. Constitutive Relationship for Hot Deformation of TB18 Titanium Alloy. Adv. Mater. Sci. Eng. 2020, 2020, 5716548. [CrossRef]

6. Liu, X.; Zhu, L.; Zhang, Q. Analysis of TA2 hot deformation behavior and corrected TA2 constitutive model based on dynamic recrystallization. Mater. Res. Express 2018, 6, 046531. [CrossRef] 
7. Chen, X.; Zhang, J.; Du, Y.; Wang, G.; Huang, T. Dynamic Recrystallization Simulation for X12 Alloy Steel by CA Method Based on Modified L-J Dislocation Density Model. Metals 2019, 9, 1291. [CrossRef]

8. Li, M.; Duan, Y.; Yao, D.; Guan, Y.; Yang, L. Constitutive Model and Flow Behavior of B1500HS High-Strength Steel during the Hot Deformation Process. Metals 2019, 10, 64. [CrossRef]

9. Estrin, Y.; Mecking, H. A unified phenomenological description of work hardening and creep based on one-parameter models. Acta Met. 1984, 32, 57-70. [CrossRef]

10. Zhang, J.-Y.; Jiang, P.; Zhu, Z.-L.; Chen, Q.; Zhou, J.; Meng, Y. Tensile properties and strain hardening mechanism of Cr-Mn-Si-Ni alloyed ultra-strength steel at different temperatures and strain rates. J. Alloys Compd. 2020, 842, 155856. [CrossRef]

11. Yang, H.; Yao, P.; Liu, H. Study on austenite recrystallization softening behavior of GCr15 steel. IOP Conf. Ser. Mater. Sci. Eng. 2019, 493, 012034. [CrossRef]

12. Xu, Y.; Zhao, Y.; Liu, J. A modified kinetics model and softening behavior for static recrystallization of $12 \mathrm{Cr}$ ultra-super-critical rotor steel. Mater. Res. Express 2020, 7, 056507. [CrossRef]

13. Su, Z.; Li, N.; Sun, C.; Zhao, J.; Wang, C.; Qian, L. Strain rate-dependent hardening with dislocation-twin interaction of Fe-Mn-Al-C steel using crystal plasticity. Mater. Sci. Technol. 2019, 35, 1436-1447. [CrossRef]

14. Yadav, S.D.; Vijayanand, V.D.; Nandgopal, M.; Reddy, G.V.P. On the tensile flow stress response of $304 \mathrm{HCu}$ stainless steel employing a dislocation density based model and electron backscatter diffraction measurements. Philos. Mag. 2019, 100, 312-336. [CrossRef]

15. Imran, M.; Szyndler, J.; Afzal, M.J.; Bambach, M. Dynamic recrystallization-dependent damage modeling during hot forming. Int. J. Damage Mech. 2019, 29, 335-363. [CrossRef]

16. Mishra, S.; Yadava, M.; Kulkarni, K.N.; Gurao, N. A new phenomenological approach for modeling strain hardening behavior of face centered cubic materials. Acta Mater. 2019, 178, 99-113. [CrossRef]

17. Zenasni, Z.; Haterbouch, M.; Atmani, Z.; Atlati, S.; Zenasni, M.; Nasri, K.; Oussouaddi, O. Physics-based plasticity model incorporating microstructure changes for severe plastic deformation. Comptes Rendus Mécanique 2019, 347, 601-614. [CrossRef]

18. He, X.; Liu, L.; Zeng, T.; Yao, Y. Micromechanical modeling of work hardening for coupling microstructure evolution, dynamic recovery and recrystallization: Application to high entropy alloys. Int. J. Mech. Sci. 2020, 177, 105567. [CrossRef]

19. Bong, H.J.; Lee, J.; Lee, M.G. Identification of mechanical responses of steel sheets under non-proportional loadings using dislocation-density based crystal plasticity model. Int. J. Mech. Sci. 2019, 155, 461-474. [CrossRef]

20. Speich, G.R. Metals Handbook Vol. 1 Properties and Selection Irons and Steels, Ultrahigh-Strength Steels Section; ASM International: Materials Park, OH, USA, 2005; pp. 1118-1170.

21. Liu, J.; Liu, Y.; Lin, H.; Li, M. The metadynamic recrystallization in the two-stage isothermal compression of 300M steel. Mater. Sci. Eng. A 2013, 565, 126-131. [CrossRef]

22. Liu, Y.G.; Liu, J.; Li, M.; Lin, H. The study on kinetics of static recrystallization in the two-stage isothermal compression of 300M steel. Comput. Mater. Sci. 2014, 84, 115-121. [CrossRef]

23. Luo, J.; Liu, Y.; Li, M.-Q. Three-dimensional Numerical Simulation and Experimental Analysis of Austenite Grain Growth Behavior in Hot Forging Processes of 300M Steel Large Components. J. Iron Steel Res. Int. 2016, 23, 1012-1019. [CrossRef]

24. Zhao, M.; Huang, L.; Zeng, R.; Wen, D.; Su, H.; Li, J. In-situ observations and modeling of static recrystallization in $300 \mathrm{M}$ steel. Mater. Sci. Eng. A 2019, 765, 138300. [CrossRef]

25. Zhao, M.; Huang, L.; Zeng, R. In-situ observations and modeling of metadynamic recrystallization in 300M steel. Mater. Charact. 2020, 159, 109997. [CrossRef]

26. Zeng, R.; Huang, L.; Li, J. Quantification of multiple softening processes occurring during multi-stage thermoforming of high-strength steel. Int. J. Plast. 2019, 120, 64-87. [CrossRef]

27. Chen, R.; Zeng, J.; Yao, G.; Feng, F. Flow-Stress Model of 300M Steel for Multi-Pass Compression. Metals 2020, 10, 438. [CrossRef]

28. Chen, R.; Zhang, S.; Liu, X.; Feng, F. A Flow Stress Model of 300M Steel for Isothermal Tension. Materials 2021, 14, 252. [CrossRef]

29. Chen, R.; Zheng, Z.; Li, J.; Li, N.; Feng, F. In Situ Investigation of Grain Evolution of 300M Steel in Isothermal Holding Process. Materials 2018, 11, 1862. [CrossRef]

30. Sakai, T.; Belyakov, A.; Kaibyshev, R.; Miura, H.; Jonas, J.J. Dynamic and post-dynamic recrystallization under hot, cold and severe plastic deformation conditions. Prog. Mater. Sci. 2014, 60, 130-207. [CrossRef]

31. Liu, Y.-X.; Lin, Y.; Li, H.-B.; Wen, D.-X.; Chen, X.-M.; Chen, M.-S. Study of dynamic recrystallization in a Ni-based superalloy by experiments and cellular automaton model. Mater. Sci. Eng. A 2015, 626, 432-440. [CrossRef]

32. Chen, R.; Guo, P.; Zheng, Z.; Li, J.; Feng, F. Dislocation Based Flow Stress Model of 300M Steel in Isothermal Compression Process. Materials 2018, 11, 972. [CrossRef] [PubMed]

33. Laasraoui, A.; Jonas, J.J. Prediction of steel flow stresses at high temperatures and strain rates. Met. Mater. Trans. A 1991, 22, 1545-1558. [CrossRef] 